\title{
A FRAMEWORK FOR ERROR ANALYSIS OF A LONG-RANGE TRANSPORT MODEL WITH EMPHASIS ON PARAMETER UNCERTAINTY
}

Joseph Alcamo and Jerzy Bartnicki

International Institute for Applied Systems Analysis

Laxenburg, Austria

RR-87-23

December 1987

Reprinted from Atmospheric Environment, volume 21 (1987).

INTERNATIONAL INSTITUTE FOR APPLIED SYSTEMS ANALYSIS

Laxenburg, Austria 
Research Reports, which record research conducted at IIASA, are independently reviewed before publication. However, the views and opinions they express are not necessarily those of the Institute or the National Member Organizations that support it.

Reprinted with permission from Atmospheric Environment, 21 (1987), 2121-2131. Copyright (c) 1987, Pergamon Journals Ltd (UK).

All rights reserved. No part of this publication may be reproduced or transmitted in any form or by any means, electronic or mechanical, including photocopy, recording, or any information storage or retrieval system, without permission in writing from the copyright holder.

Printed by Novographic, Vienna, Austria 


\section{FOREWORD}

An important part of IIASA's research program has always been the practical application of models in environmental management studies. As an example, the Acid Rain Project relies on computer models of the atmosphere to determine how pollutants emitted in one part of Europe are distributed to other parts of Europe. Because of the crucial role of these models in selecting pollution control strategies, it is natural that some of our research now focuses on their uncertainty. The following paper is a product of this research. Though the article describes the uncertainty of a long-range transport model, it produces an analytical framework that could be useful for studying the uncertainty of other environmental models.

R.E. MUNN

Leader

Environment Program 
( 


\title{
A FRAMEWORK FOR ERROR ANALYSIS OF A LONG- RANGE TRANSPORT MODEL WITH EMPHASIS ON PARAMETER UNCERTAINTY
}

\author{
Joseph AlCAMo and Jerzy BARTNICKI* \\ IIASA, A-2361 Laxenburg, Austria
}

(First received 23 December 1986 and received for publication 3 April 1987)

\begin{abstract}
A comprehensive framework for model error analysis is applied to the EMEP-W model of longrange transport of sulfur in Europe. This framework includes a proposed taxonomy of model uncertainties. Parameter uncertainties were investigated by Monte Carlo simulation of two source-receptor combinations. A $20 \%$ input parameter uncertainty (expressed as a coefficient of variation $=$ standard deviation $/ \mathrm{mean}$ ) yielded a $15-22 \%$ output error of total sulfur deposition. The relationship between output error and input uncertainty was approximately proportional. Covariance between parameters can have an important effect on computed model error, and can either exaggerate or reduce errors compared to the uncorrelated case. Of the model state variables, $\mathrm{SO}_{2}$ air concentration and wet deposition had the highest error, and total sulfur deposition the lowest. It was also found that it is more important to specify the dispersion of the input parameter frequency distributions than their shape. The resuits of the model error analysis were applied to routine calculations of deposition in Europe. An error (coefficient of variation) of $20 \%$ for transfer coefficients throughout Europe yielded spatial variations in the order of a few tens to a few hundreds of $\mathrm{km}$ in computed deposition isolines of 2 and $5 \mathrm{~g}$ sulfur $\mathrm{m}^{-2} \mathrm{a}^{-1}$.
\end{abstract}

Key word index: Error analysis, interregional modeling, long-range transport, model evaluation, uncertainty analysis, parameter uncertainty.

\section{INTRODUCTION}

Long-range transport (LRT) models are often used as tools to gain understanding about the relationship

* On leave from Institute for Meteorology and Water Management in Warsaw.

$\dagger$ There is a terminology problem in describing the analysis presented in this paper. Error analysis, uncertainty analysis and sensitivity analysis are terms used to describe similar approaches with similar objectives in the fields of atmospheric science, decision science, ecology, risk analysis, applied mathematics and other fields (see, e.g., Clifford, 1973; Gardner et al., 1980; Tilden and Seinfeld, 1982; Beck and van Straten, 1983; Morgan et al., 1984; Freeman et al., 1986).

Some researchers believe that an analysis of this type should be called sensitivity analysis unless it involves comparisons of model output with observations. We disagree because we believe that sensitivity analysis has the strict definition $s=\partial \mathbf{Y} / \partial \mathbf{X}$ where $\mathbf{X}$ and $\mathbf{Y}$ are vectors defined in Equation (3). Rather than compute a partial derivative, we wish to estimate the difference expressed in Equation (4). We agree, however, that sensitivity analysis is commonly a part of an uncertainty or error analysis.

In this paper we use the term model error analysis to describe our procedure because we are examining the error of a mathematical model, where a mathematical model is a set of variables and coefficients related together in mathematical equations. This error can be estimated by comparing model output to observations (though there are drawbacks to this approach as we point out) or by stochastically analysing the model equations as we do in this paper. As for the source of this model error, we prefer the term input uncertainty rather than error because the input in question may in fact be stochastic in nature, as in the case of precipitation inputs. Hence these inputs may be inherently uncertain rather than erroneously estimated by the model user. between emission sources and distant receptors. In fact, they now hold a central place in the analysis of transboundary air pollution problems (see, e.g., U.S. National Research Council, 1983 or OECD, 1979). With their importance follows naturally the need to evaluate their accuracy. An approach to model evaluation termed model error analysis $†$ is outlined in this paper, and is offered as an additional technique to complement (rather than replace) current methods for evaluating models such as validation and verification.

Related analyses have been conducted in water quality modeling (see, e.g., Burges and Littenmaier, 1975; Fedra et al., 1981 or Beck and van Straten, 1983) and in modeling other ecological systems (e.g. Gardner et al., 1980). The topic of uncertainty in atmospheric modeling has also attracted attention at recent symposia (Demerjian, 1984; Fox, 1984; Carson, 1986). However, these symposia did not discuss in detail the type of framework and quantitative methods presented in this paper. Tilden and Seinfeld (1982) approached the problem of parameter uncertainty of an airbasin photochemical air pollution model with the so-called FAST method (Fourier Amplitude Sensitivity Test). Freeman et al. (1986) used first order equations to examine the effect of various input uncertainties on output of a Gaussian dispersion model. Morgan et al. (1984) used Monte Carlo simulation to examine parameter uncertainties in a simple Lagrangian model.

In this paper we present a framework for different types of model uncertainties and for several steps in 
model error analysis from problem formulation to the application of results in routine model calculations. The framework is applied to the LRT model of sulfur in Europe developed by the Western Meteorological Synthesizing Center of EMEP (EMEP-W) (Eliassen and Saltbones, 1983) (the basic equations of this model are presented in Appendix A). Quantitative results are presented for one aspect of this analysis-parameter uncertainty.

The objective of model error analysis as presented in this paper is to quantify error of model output and apply this information to routine model calculations as a source of additional information for model users. This analysis can be applied to already validated models. This information can also assist in further model development and help identify research priorities.

\section{PROCEDURE FOR ANALYSIS}

We propose the following procedure for model error analysis: (1) problem formulation, in which time and space scales of the problem are established, (2) inventory of uncertainties, to collect possible sources of error in a systematic fashion, (3) screening and ranking of uncertainties, to set priorities for quantitative evaluations, (4) quantitative evaluation of uncertainties which draws on a variety of analytical techniques, and finally (5) application to routine calculations in which information about model error is used to supplement routine calculations.

\section{PROBLEM FORMULATION}

The error of a model depends very much on the time and space scales under consideration and how the model is used. For instance, it is intuitively clear that an annual average computation of sulfur deposition will have a smaller error than the daily average values. Moreover, if an LRT model is used, for instance, to evaluate the impact of different future emission scenarios, then the uncertainty of future emissions does not affect model error. Consequently time and space scales and prospective model use must be specified as a first step in this analysis. In this paper we are particularly interested in using the LRT model for evaluating sulfur emission control strategies as part of an integrated analysis of acidification in Europe (see, e.g., Alcamo et al., 1985 and Hordijk, 1985). For computational simplicity, we wish to use model results in the form of transfer matrices and to express the error of each of the transfer coefficients. Therefore, we are concerned with country-scale sulfur emission and grid-scale sulfur deposition (total, wet, dry) and airborne sulfur $\left(\mathrm{SO}_{2}\right.$ and $\mathrm{SO}_{4}^{2-}$ ). This may be expressed in the EMEP model grid system (Appendix A) as:

$$
d_{j k}=\sum S_{i} \alpha_{i j k}+b_{j k}
$$

in which $d_{j k}$ is the deposition $\left(\mathrm{g} \mathrm{m}^{-2} \mathrm{a}^{-1}\right)$ at grid location $(j, k)$ due to the sum of all country contributions, $S_{i}$ is the emission from country $i, \alpha_{i j k}$ is the transfer coefficient $\left(\mathrm{g} \mathrm{m}^{-2} \mathrm{a}^{-1}\right.$ sulfur deposition per $\mathrm{ta}^{-1}$ sulfur emitted), and $b_{j k}$ is the background deposition. A similar expression can be written for airborne sulfur. We are particularly interested in the interval:

$$
d_{j k}-\delta_{j k}<d_{j k}<d_{j k}+\delta_{j k}
$$

where we assume $\delta_{i k}$ to be an estimate of the error of $d_{j k}$.

\section{INVENTORY}

To help make the assembling of uncertainties more systematic, we propose the following taxonomy which classifies uncertainties in terms of model characteristics: (1) model structure-these are uncertainties resulting from the specified collection of model terms and how they are related, containing all physical assumptions of the model; (2) parameters-uncertainties from coefficients which are constant in time or space; (3) forcing functions-uncertainties from coefficients which inherently change in time and space; (4) initial state-uncertainties related to boundary and initial conditions; and (5) model operationuncertainties owing to the solution techniques of model equations and pre- and post-processing of model information.

A further distinction is made between diagnostic and prognostic uncertainty. Diagnostic uncertainty refers to use of the model to describe past or current conditions whereas prognostic obviously refers to model use for forecasting.

It is important to note that the above taxonomy is hierarchically organized in that parameter, forcing function, and all other uncertainties depend on the model structure of interest.

We apply this taxonomy to the EMEP-W model in Table 1. Note that certain uncertainties have both a diagnostic and prognostic component (parameter estimation errors, for example) whereas others (uncertain meteorological inputs and interannual meteorological variability) are important for the diagnostic or prognostic cases alone. This emphasizes the need to specify the use of the model before assessing its uncertainty.

\section{SCREENING AND RANKING}

After compiling an inventory as in Table 1, it is usually unrealistic to quantify each of the specified uncertainties. Consequently, in this step we try to identify the more important uncertainty sources. Conventional sensitivity analysis (varying one coefficient to its extreme values while keeping other coefficients constant) or a priori judgement may be used. In our study we have given second priority to particular sources of uncertainty. For example, the omission of horizontal diffusion in the EMEP-W 
Table 1. Model uncertainty taxonomy (with EMEPW examples)

\begin{tabular}{|c|c|c|}
\hline $\begin{array}{l}\text { Type of } \\
\text { uncertainty }\end{array}$ & $\begin{array}{l}\text { Diagnostic } \\
\text { (past/current) }\end{array}$ & $\begin{array}{l}\text { Prognostic } \\
\text { (forecasting) }\end{array}$ \\
\hline $\begin{array}{l}\text { Model } \\
\text { structure }\end{array}$ & Linearity & Linearity \\
\hline Parameters & $\begin{array}{l}\text { Parameter } \\
\text { estimation } \\
\text { errors }\end{array}$ & $\begin{array}{l}\text { Parameter } \\
\text { estimation } \\
\text { errors }\end{array}$ \\
\hline \multirow[t]{3}{*}{$\begin{array}{l}\text { Forcing } \\
\text { functions }\end{array}$} & $\begin{array}{l}\text { Spatial } \\
\text { distribution } \\
\text { emissions }\end{array}$ & $\begin{array}{l}\text { Future } \\
\text { emissions }\end{array}$ \\
\hline & $\begin{array}{l}\text { Total } \\
\text { country } \\
\text { emissions }\end{array}$ & \\
\hline & $\begin{array}{l}\text { Uncertain } \\
\text { meteorologic } \\
\text { inputs }\end{array}$ & $\begin{array}{l}\text { Interannual } \\
\text { meteorologic } \\
\text { variability }\end{array}$ \\
\hline $\begin{array}{l}\text { Initial } \\
\text { state }\end{array}$ & $\begin{array}{l}\text { Initial and } \\
\text { boundary } \\
\text { condition } \\
\text { estimation } \\
\text { errors }\end{array}$ & $\begin{array}{l}\text { Future } \\
\text { initial and } \\
\text { boundary } \\
\text { conditions }\end{array}$ \\
\hline \multirow[t]{3}{*}{$\begin{array}{l}\text { Model } \\
\text { operation }\end{array}$} & $\begin{array}{l}\text { Trajectory } \\
\text { estimation } \\
\text { errors }\end{array}$ & $\begin{array}{l}\text { Trajectory } \\
\text { estimation } \\
\text { errors }\end{array}$ \\
\hline & $\begin{array}{l}\text { Solution of } \\
\text { concentration } \\
\text { equations }\end{array}$ & $\begin{array}{l}\text { Solution of } \\
\text { concentration } \\
\text { equations }\end{array}$ \\
\hline & $\begin{array}{l}\text { Processing of } \\
\text { meteorologic } \\
\text { data }\end{array}$ & \\
\hline
\end{tabular}

model is not thought to be a large source of error because of the spatial scales treated by the model. Another type of uncertainty, due to the trajectory calculation method, was found to be unimportant in typical EMEP-W applications (OECD, 1979). For additional discussion of ranking uncertainties the reader is referred to Alcamo and Bartnicki (1985). We now concentrate on quantitatively evaluating the remaining uncertainties.

\section{QUANTITATIVE EVALUATION OF MODEL ERROR}

For the discussion of quantitative methods we introduce the general model:

$$
\mathbf{Y}=\hat{\mathbf{G}}(\mathbf{X})
$$

where $\mathbf{X}$ and $\mathbf{Y}$ are vectors of model inputs and outputs, respectively and $\hat{\mathbf{G}}$ is an operator acting on $\mathbf{X}$.

We assume that 'true values' of the output are equal to $\mathbf{Y}^{\prime}$ and define model error $\varepsilon$, as

$$
\varepsilon=\mathbf{Y}-\mathbf{Y}^{\prime} \text {. }
$$

One way to estimate $\varepsilon$ is to compare model output with observations. The developers of the EMEP model have extensively tested model output against observed air concentrations of $\mathrm{SO}_{2}$ and $\mathrm{SO}_{4}^{2-}$ in rain. These comparisons have led to the conclusion that model output agrees reasonably well with long-term average air concentrations of $\mathrm{SO}_{2}$ and $\mathrm{SO}_{4}^{2-}$ (Eliassen and Saltbones, 1983). However, the undeveloped state of dry deposition measurements made it difficult to compare model output with dry deposition, and hence total deposition, observations.

In general, comparison of any model's output with observations is usually insufficient to estimate $\varepsilon$ because: (1) observations are often unreliable due to incorrect or inconsistent measurement techniques, (2) model output is not necessarily 'observable', especially for the highly aggregated spatial and temporal scales as is common in LRT modeling, (3) certain important cause-effect relations may not be readily observable as in the case of the influence of a single country's pollutant emissions on pollutant deposition at a distant receptor, (4) agreement of model output with data does not settle the question of uncertainty when the model is used for forecasting, (5) parameters in some models may be easily 'tuned' such that output closely agrees with data, (6) it is usually impossible to assemble data for a comprehensive range of environmental conditions. Despite the previous caveats, comparisons of model output with data provide the only sure benchmark of a model's relationship to reality. As such we believe that comparison of model output with measurements is necessary though insufficient for assessing model error.

Because of the difficulty in using comparison of model output with data to estimate $\varepsilon$, we take an indirect approach and estimate $\delta_{j k}$ in Equation (2) which is an approximation of $\varepsilon$. In our investigations we have not identified a single good mathematical approach, but rely on different methods for evaluating model error due to different model uncertainties. As examples: to investigate error due to non-linearity we have compared different model structures under identical environmental conditions (Alcamo and Bartnicki, 1986); for error due to interannual meteorologic variability we have conducted matrix analysis (Alcamo and Posch, 1986); and for error due to geographic distribution of emissions we used an analytical solution of the variance equations (Alcamo, 1987). A discussion of these methods and their results is outside the scope of this paper. The remainder of this paper concentrates on a method to assess model error due to parameter uncertainty.

\section{MONTE CARLO SIMULATION}

Parameters in the LRT model represent many rather complicated physical/chemical processes which occur in nature. In addition, they represent values averaged over a grid element and transport time, or time step of the numerical integration. Since it is usually impossible to measure these values directly, they have to be estimated from either theoretical considerations or numerical experiments. In both cases the final value of 
the parameter has limited accuracy, i.e. there is only a certain probability that the parameter value used in the model is the correct one.

We use Monte Carlo simulation to quantify model error resulting from parameter uncertainty by substituting frequency distributions for deterministic parameter values. As a result we compute frequency distributions for the model state variables. The output frequency distributions reflect model error due to parameter uncertainty. The Monte Carlo simulation is rather flexible and can be applied to a wide class of LRT models, both linear and non-linear.

For the EMEP model we define the terms in Equation (3) as

$$
\begin{aligned}
& Y=\left(c_{1}, c_{2}, d_{\mathrm{w}}, d_{\mathrm{d}}, d_{\mathrm{t}}\right) \\
& X=\left(\beta_{1}, \ldots, \beta_{m}, \varphi_{1}(x, t), \ldots, \varphi_{n}(x, t)\right)
\end{aligned}
$$

where

$$
\begin{aligned}
c_{1}, c_{2}, d_{\mathrm{w}}, d_{\mathrm{d}}, d_{\mathrm{t}}= & \begin{array}{l}
\text { EMEP state variables: } \mathrm{SO}_{2} \\
\text { air concentration, } \mathrm{SO}_{4}^{2-} \text { air } \\
\text { concentration, wet sulfur de- } \\
\text { position, dry sulfur depo- } \\
\text { sition, total deposition }
\end{array} \\
\beta_{1}, \ldots, \beta_{m}= & \text { parameters defined in Table } \\
& 2 \\
\varphi_{1}(x, t), \ldots, \varphi_{n}(x, t)= & \text { forcing functions: sulfur } \\
& \text { emissions, wind velocity and } \\
& \text { precipitation. }
\end{aligned}
$$

The operator $\hat{G}$ represents two differential and five algebraic EMEP model equations as presented in Appendix A. For the model defined above, the Monte Carlo method is applied in the following way.

Using random numbers $v_{1}, \ldots, v_{m} \in[0,1]$ we sample from the frequency distribution $f(\beta)$ and obtain a $\beta^{i}$ such that $f\left(\beta^{i}\right)=v_{i}$. Each $\beta^{i}$ is used to compute $Y$ by Equations (A.1)-(A.7). An individual computation of $Y$ is called a 'realization' of $Y$. We repeat this sampling and computation $N$ times, until a statistically significant sample* of $v$ is drawn (for results in this paper, a minimum of 400 and a maximum of 1500 runs were required). We then compute the frequency distribution $f(Y)$ from the set of realizations of $Y$. The frequency distribution $f(Y)$ indicates the error of the state variables due to uncertainty reflected in $f(\beta)$.

The input and output frequency distributions are presented in the form of histograms with 10 discrete classes. Using discrete rather than continuous frequency distributions speeds computations and allows easy specification of these distributions.

The preceding method has been applied to 1980 meteorological and emission conditions. Two source-receptor combinations have been tested: (1)

* During the computations, we compare the output frequency distributions from the present and previous runs. We call a sample 'statistically significant', if the difference between classes in current and previous runs is less than $1 \%$.
German Democratic Republic (G.D.R.), as emission source, and Illmitz (Eastern Austria) as a receptor grid, and United Kingdom (U.K.) to Rörvik (Southern Sweden). These two combinations were selected because of their contrasting meteorological, geographic and emission situations. In Fig. 1 we present assigned frequency distributions for the parameters $\alpha$ and $v_{d}$. These parameter uncertainty estimates are discussed in the next section. The computed $\mathrm{SO}_{2}$ and total sulfur deposition are given in Fig. 2.

\section{SELECTION OF INPUT FREQUENCY DISTRIBUTIONS}

A key exercise in the Monte Carlo procedure described above is to prescribe parameter frequency distributions which reflect parameter uncertainty. The question arises, should these distributions reflect daily, monthly, yearly or other temporal variation? In fact, the highly aggregated nature of the current EMEP-W model makes it difficult to select appropriate frequency distributions for parameters, in the same way that it is difficult to relate an annual- and European-average $v_{d}$ to observable phenomena. The revised version of EMEP-W (Lehmhaus et al., 1986) contains seasonally varying parameters which are consequently easier to relate to observable phenomena. With these caveats in mind, we interpret $f(\alpha)$ and $f\left(v_{\mathrm{d}}\right)$ in Fig. 1 in accordance with the time scale of the problem, i.e. as uncertainty of annual average parameter values. For further interpretation, we consider three important aspects of frequency distributions: central tendency, dispersion and shape.

One interpretation of central tendency is to assume that it reflects the calibrated/verified model value. For instance, in Fig. 1 the 'modes' of $f\left(v_{\mathrm{d}}\right)$ and $f(\alpha)$ are assigned the EMEP values of $8.0 \times 10^{-3} \mathrm{~m} \mathrm{~s}^{-1}$ and 0.15 , respectively.

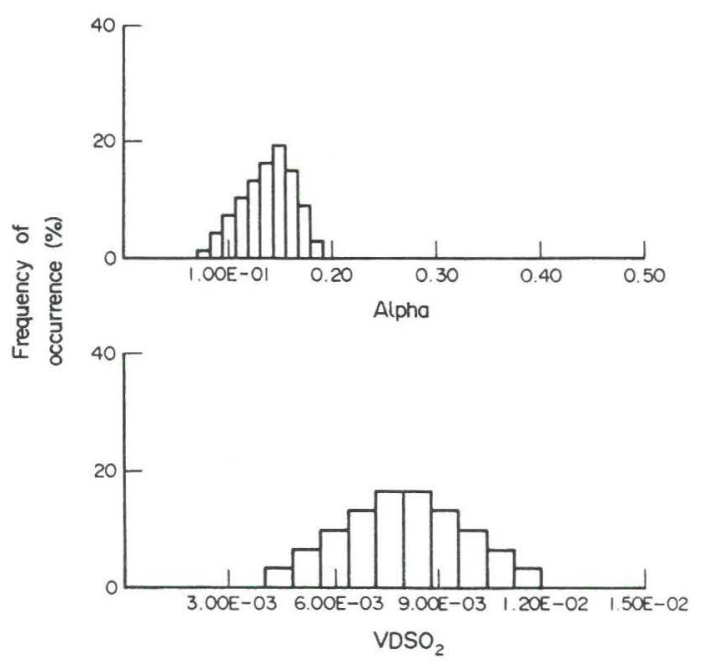

Fig. 1. Assigned frequency distributions for the parameters $\alpha$ and $v_{\mathrm{d}}$. 
Dispersion can be estimated a priori from either observations or model calculations. In the case of Fig. 1, the range of $f(\alpha)$ is taken from Högstrom's (1979) analysis of the geographic variability of the local deposition in Europe. The range of $f\left(v_{d}\right)$ is estimated from average field values presented in McMahon and Denison (1979). We must emphasize that these are only sample references for setting the ranges of parameter frequency distributions. Other ranges, whether they are based on observations or theoretical calculations. may also be used as long as they represent averages over large spatial and temporal scales.
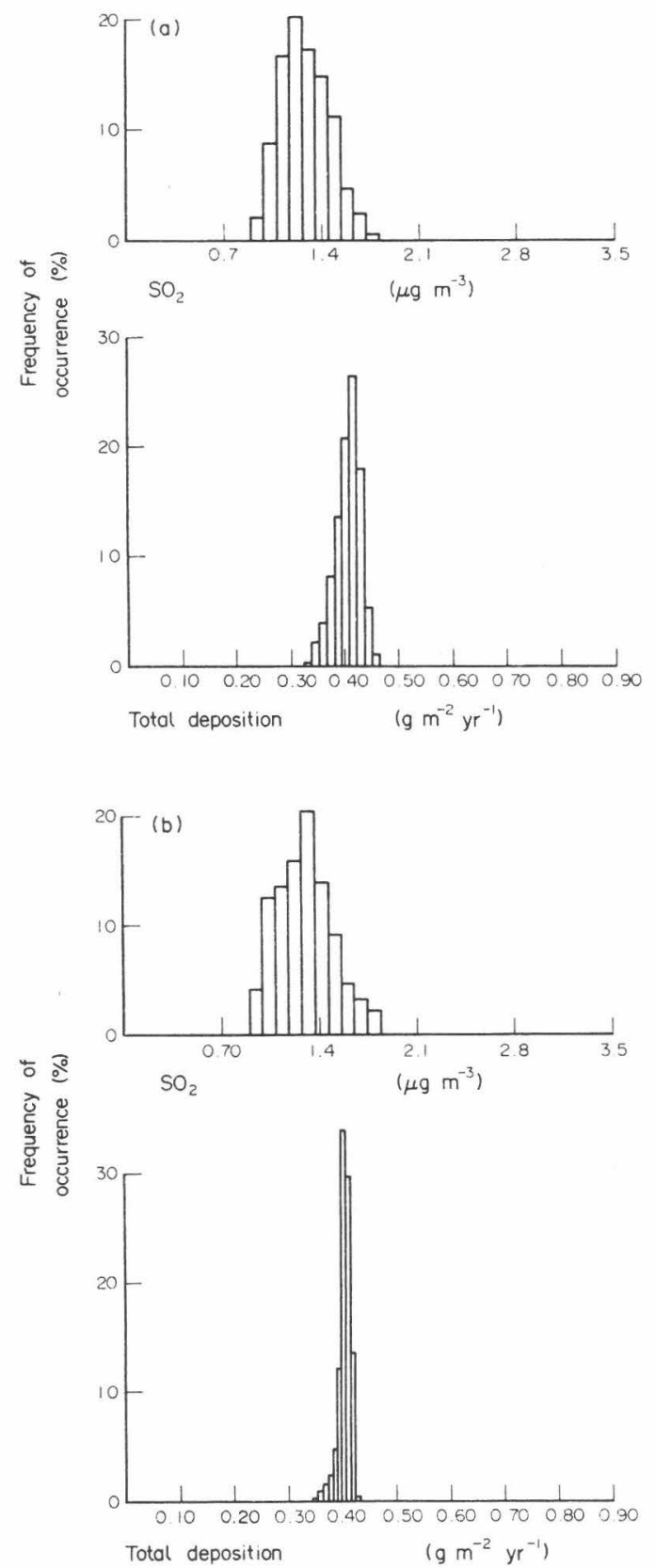

Fig. 2(a-b)

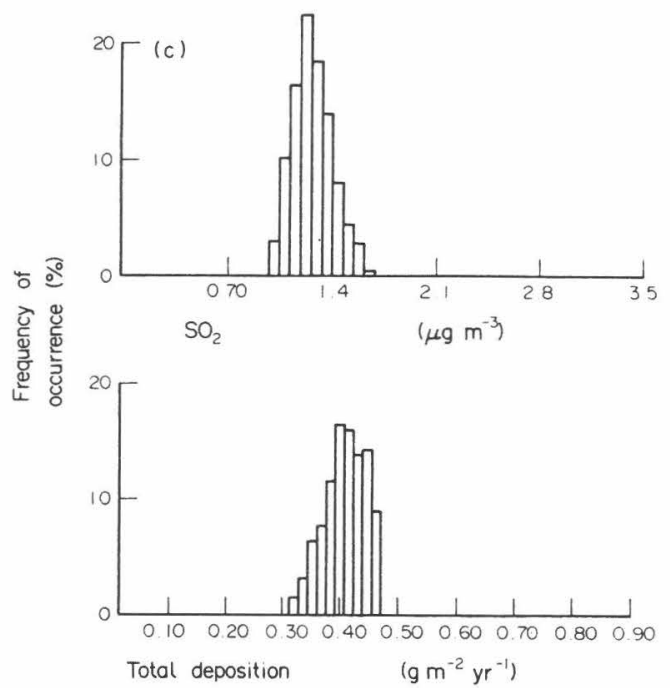

Fig. 2. Frequency distributions of computed $\mathrm{SO}_{2}$ concentration and total sulfur deposition at Illmitz due to uncertain $\alpha$ and $v_{\mathrm{d}}$ : (a) assuming independent parameters, (b) assuming positive correlation between $v_{\mathrm{d}}$ and $\alpha$, and

(c) assuming negative correlation between $v_{\mathrm{d}}$ and $\alpha$.

The third important measure is the shape of the distribution. With only information about range, Tiwari and Hobbie (1976) have noted that a uniform distribution is the default distribution. O'Neill et al. (1982) pointed out that with an additional estimate of central tendency, the default distribution is triangular. Gardner (personal communication) in modeling ecological systems has noted that, in certain cases, different shapes of input distributions with identical standard deviations produced very similar output distributions. If this is true it would reduce one problem in specifying parameter frequency distributions, i.e. selecting the shape of distribution. To test this hypothesis for the EMEP model we examined four different distribution shapes (uniform, triangular, truncated normal and irregular, shown in Fig. 3) each with $20.4 \%$ coefficient of variation* (standard deviation divided by mean). These different distributions were assigned to nine of the 10 EMEP parameters. (Strictly speaking, parameter $b$ in Table 2, should be viewed as a source of boundary condition uncertainty rather than parameter uncertainty. Therefore it is not included in this analysis.)

For both source-receptor combinations (G.D.R.Illmitz and U.K.-Rörvik) and for all distributions, the difference between the mean of the Monte Carlo simulation and the computed deterministic value is less than $5 \%$. This is not surprising considering the

* This corresponds to a triangular distribution with a $\pm 50 \%$ range around the mean which is thought by the authors to be a reasonable estimate of their uncertainty. 


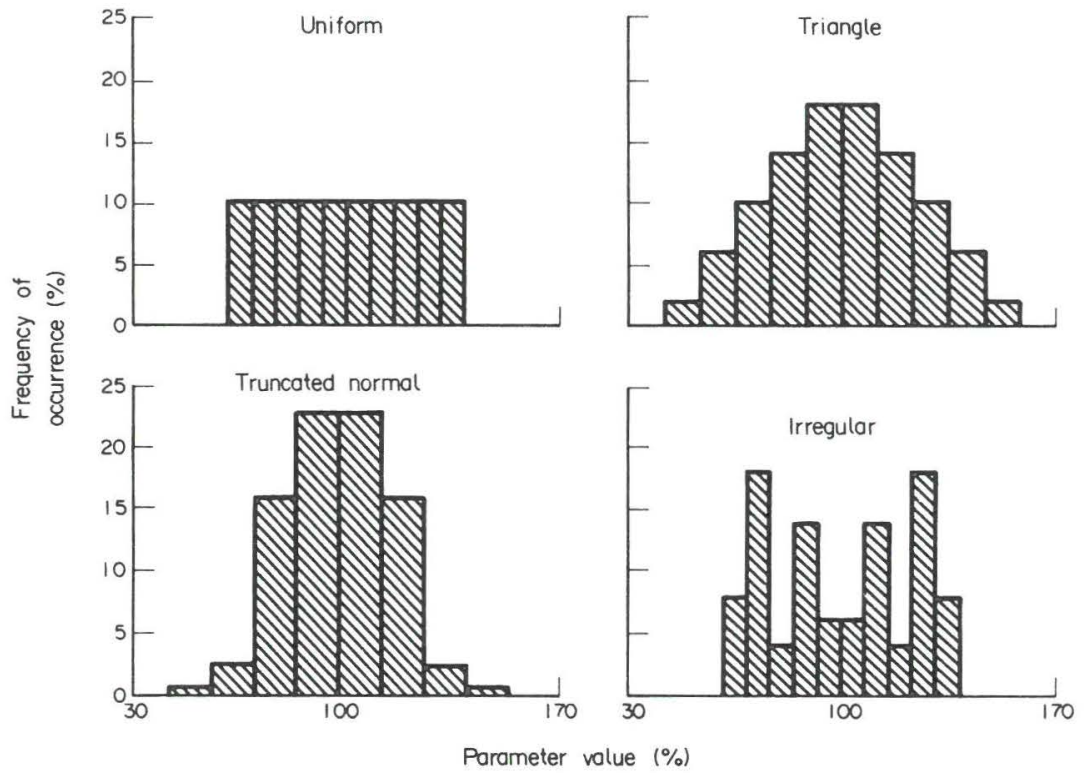

Fig. 3. Distribution shapes with identical coefficient of variation $(20.4 \%)$.

Table 2. Parameter values in EMEP long-range transport model (from Eliassen and Saltbones, 1983)

\begin{tabular}{|c|c|c|c|}
\hline Parameter & Explanation & Value & Unit \\
\hline $\begin{array}{l}v_{d} \\
v_{\mathrm{ds}} \\
h \\
k_{\mathrm{t}} \\
k_{\mathrm{w}}\end{array}$ & $\begin{array}{l}\text { Deposition velocity for } \mathrm{SO}_{2} \\
\text { Deposition velocity for } \mathrm{SO}_{4}^{2-} \\
\text { Mixing height } \\
\text { Transformation rate of } \mathrm{SO}_{2} \text { to } \mathrm{SO}_{4}^{2-} \\
\text { Wet deposition rate of } \mathrm{SO}_{2} \text {, used only in grid } \\
\text { elements and 6-h periods when it rains } \\
\text { Additional dry deposition in the same grid } \\
\text { square where emission occurs } \\
\text { Part of sulfur emission assumed to be emitted } \\
\text { directly as salfate } \\
\text { Overall decay rate for } \mathrm{SO}_{4}^{2-} \\
\text { Proportionality coefficient in Equation (A.4) } \\
\text { Background concentration in Equation (A.4) } \\
\text { In Finland and Norway } \\
\text { In other countries }\end{array}$ & $\begin{array}{c}8 \times 10^{-3} \\
2 \times 10^{-3} \\
1000 \\
2 \times 10^{-6} \\
3 \times 10^{-5} \\
0.15 \\
0.05 \\
4 \times 10^{-6} \\
0.69 \times 10^{6}\end{array}$ & $\begin{array}{l}\mathrm{m} \mathrm{s}^{-1} \\
\mathrm{~m} \mathrm{~s}^{-1} \\
\mathrm{~m} \\
\mathrm{~s}^{-1} \\
\mathrm{~s}^{-1} \\
\text { dimensionless } \\
\text { dimensionless } \\
\mathrm{s}^{-1} \\
\text { dimensionless } \\
\mathrm{mg} \mathrm{S} \ell^{-1} \\
\mathrm{mg} \mathrm{S} \ell^{-1}\end{array}$ \\
\hline
\end{tabular}

symmetry of the input distributions. Computed coefficients of variation of the EMEP state variables are presented in Tables 3 and 4 . As can be seen in these tables, the four different parameter distributions produced similar coefficients of variation for a particular model state variable. The largest coefficients of variation occurred for $\mathrm{SO}_{2}$ concentration and wet deposition and the smallest for total deposition. $\mathrm{The}^{\mathrm{SO}_{2}}$ concentration may have large error because it is the only state variable not dependent, directly or indirectly, on other state variables. Total deposition, on the other hand, is the simple sum of wet and dry deposition and therefore compensates somewhat for their errors.

Since the dispersion of parameter frequency distributions is not well known, it is interesting to examine the relationship between input parameter uncertainty (coefficient of variation) and output error of the model state variables. For these model experiments, we use only triangular parameter distributions. Results for the total deposition of sulfur are shown in Fig. 4 for G.D.R.-Illmitz and U.K. Rörvik source-receptor combinations. A $20 \%$ input coefficient of variation for the nine parameters yields a coefficient of variation for total deposition of 15-22\%. For both combinations the relationship between input and output coefficients of variation is nearly proportional.

\section{COVARIANCE BETWEEN PARAMETERS}

The Monte Carlo procedure outlined above assumes that parameters are independent. By assuming the parameters in Fig. 1 are independent we compute 
Table 3. Coefficient of variation for the frequency distribution of the model state variables (per cent), transport from G.D.R. to Illmitz

\begin{tabular}{lccccc}
\hline & \multicolumn{5}{c}{ Model state variable } \\
\cline { 2 - 6 } $\begin{array}{l}\text { Parameter } \\
\text { distribution }\end{array}$ & $\mathrm{SO}_{2}$ & $\mathrm{SO}_{4}^{2-}$ & $\begin{array}{c}\text { Dry } \\
\text { deposition }\end{array}$ & $\begin{array}{c}\text { Wet } \\
\text { deposition }\end{array}$ & $\begin{array}{c}\text { Total } \\
\text { deposition }\end{array}$ \\
\hline Uniform & 20.0 & 17.4 & 16.4 & 26.9 & 14.6 \\
Triangle & 20.3 & 18.5 & 16.8 & 27.3 & 15.4 \\
Normal truncated & 20.7 & 17.8 & 17.2 & 27.7 & 15.6 \\
Irregular & 20.3 & 17.7 & 16.8 & 24.0 & 15.1 \\
\hline
\end{tabular}

Table 4. Coefficient of variation for the frequency distribution of the model state variables (per cent), transport from U.K. to Rörvik

\begin{tabular}{lccccc}
\hline & \multicolumn{5}{c}{ Model state variable } \\
\cline { 2 - 6 } $\begin{array}{l}\text { Parameter } \\
\text { distribution }\end{array}$ & $\mathrm{SO}_{2}$ & $\mathrm{SO}_{4}^{2-}$ & $\begin{array}{c}\text { Dry } \\
\text { deposition }\end{array}$ & $\begin{array}{c}\text { Wet } \\
\text { deposition }\end{array}$ & $\begin{array}{c}\text { Total } \\
\text { deposition }\end{array}$ \\
\hline Uniform & 31.1 & 19.9 & 21.5 & 26.4 & 20.2. \\
Triangle & 31.5 & 19.8 & 21.1 & 27.1 & 20.9 \\
Normal truncated & 31.4 & 20.8 & 21.9 & 26.7 & 21.1 \\
Irregular & 31.6 & 20.3 & 21.6 & 24.1 & 18.3 \\
\hline
\end{tabular}

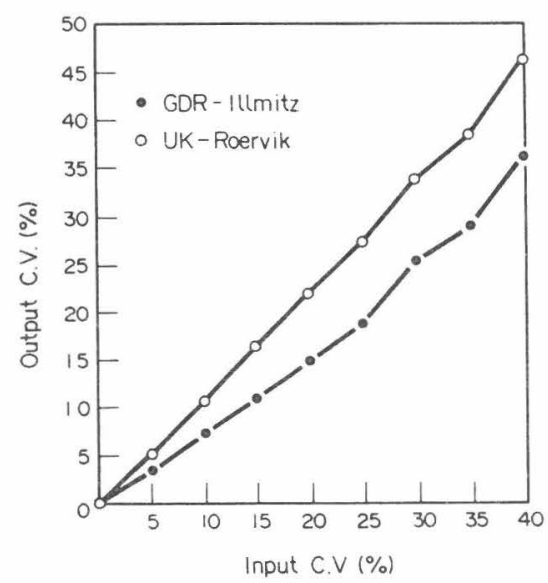

Fig. 4. Relationship between input and output coefficients of variation. Triangular distributions were used for the input parameters.

coefficients of variation of $14.2 \%$ and $6.5 \%$ for $\mathrm{SO}_{2}$ and total sulfur deposition, respectively (Fig. 2a). While the assumption of independence may be consistent with the model structure, it may nevertheless be incorrect since parameter values are often set with an implicit parameter covariance in mind. As an example, we expect the $\mathrm{SO}_{2}$ dry deposition $v_{\mathrm{d}}$ to be positively correlated with the local deposition coefficient $\alpha$ because they approximate sulfur removal processes which are affected by the same meteorological conditions. In the same way we expect the $\mathrm{SO}_{4}^{2-}$ dry deposition velocity $v_{\mathrm{ds}}$ to be positively correlated with $v_{\mathrm{d}}$. A straightforward way to account for this covariance in the Monte Carlo method is to prescribe a joint distribution of these parameters. Figure 5 accounts for a positive correlation between $v_{\mathrm{d}}$ and $\alpha$ by using

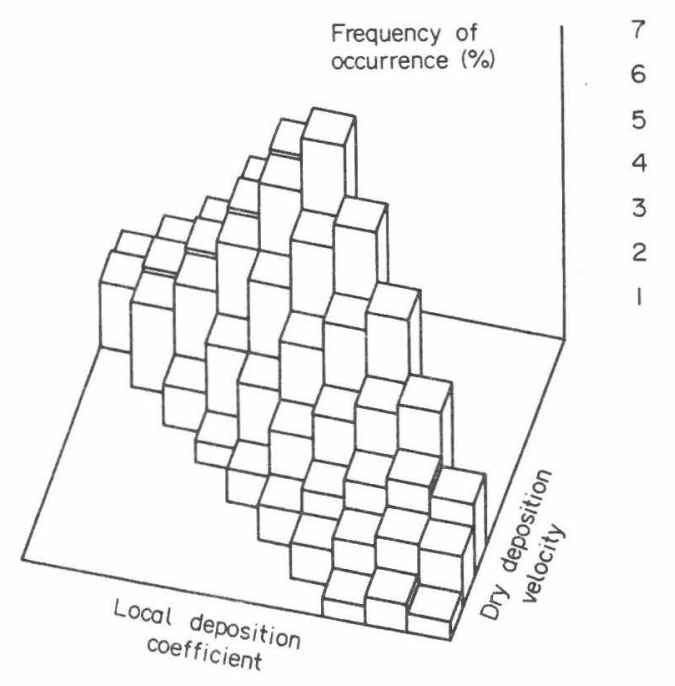

Fig. 5. Joint distribution of $v_{d}$ and $\alpha$.

$f\left(v_{\mathrm{d}}, \alpha\right)$. This joint distribution was generated by combining information of $v_{\mathrm{d}}$ vs $\alpha$ from Nordlund (1986) with the frequency distributions in Fig. 1. Figure $2 \mathrm{~b}$ notes the increase in computed $\mathrm{SO}_{2}$ error $(14.2-16.0 \%)$ and reduction in total deposition error $(6.5-3.7 \%)$ when this positive correlation is incorporated in the analysis.

When $\alpha$ and $v_{\mathrm{d}}$ are uncorrelated, one can see by the $\mathrm{SO}_{2}$ concentration Equation (A.1) that the uncertainties of these parameters sometimes compensate. However, when they are positively correlated this compensation occurs less frequently.

The change in total sulfur deposition error cannot be explained as simply as the change in $\mathrm{SO}_{2}$ error; 
however results indicate that a compensation of errors occurs within the model's system of equations.

The question arises, what is the effect of a negative correlation between $\alpha$ and $v_{\mathrm{d}}$, even if this is physically unrealistic? Figure $2 \mathrm{c}$ presents computed $\mathrm{SO}_{2}$ and total sulfur deposition for this assumption. The effect is opposite of the positive correlation case; the coefficient of variation of $\mathrm{SO}_{2}$ decreases from 14.2 to $11.3 \%$ and the coefficient of variation of total sulfur deposition increases from 6.5 to $8.9 \%$. When $v_{\mathrm{d}}$ and $\alpha$ are negatively correlated we expect their errors to compensate more frequently than in the uncorrelated case. Again by inspecting Equation (A.1) we see that negative correlation leads to a lower computed error of $\mathrm{SO}_{2}$.

\section{APPLICATION TO ROUTINE CALCULATIONS}

The quantitative evaluation described above yields estimates of deposition error at single receptor locations due to emission contributions from single countries. For routine calculations we must generalize these results to all receptors, and contributions frcm all countries, as specified in Equations (1) and (2).

To illustrate our approach we examine the special case in which only two countries contribute to the deposition of a single receptor. We also limit our attention to parameter uncertainty (and thereby neglect the last term in Equation (1) referring to background deposition). Using the symbols defined in Equations (1) we can express deposition at $(j, k)$ as:

$$
d_{j k}=S_{1} \alpha_{1 j k}+S_{2} \alpha_{2 j k} .
$$

Because $d_{j k}$ is a linear combination of uncertain $\alpha_{1 j k}$ and $\alpha_{2 j k}$ and constants $S_{1}$ and $S_{2}$, we can express its variance as:

$$
\begin{aligned}
& \sigma^{2}\left(d_{j k}\right)=S_{1}^{2} \sigma^{2}\left(\alpha_{1 j k}\right)+S_{2}^{2} \sigma^{2}\left(\alpha_{2 j k}\right) \\
& +2 S_{1} S_{2} \operatorname{cov}\left(\alpha_{1 j k}, \alpha_{2 j k}\right) .
\end{aligned}
$$

We can compute $\operatorname{cov}\left(\alpha_{1 j k}, \alpha_{2 j k}\right)$ by recalling that:

$$
\operatorname{cov}\left(\alpha_{1 j k}, \alpha_{2 j k}\right) \equiv \sigma\left(\alpha_{1 j k}\right) \sigma\left(\alpha_{2 j k}\right) \rho\left(\alpha_{1 j k}, \alpha_{2 j k}\right)
$$

where $\sigma\left(\alpha_{1 j k}\right), \sigma\left(\alpha_{2 j k}\right)$ and the correlation coefficient $\rho\left(\alpha_{1 j k}, \alpha_{2 j k}\right)$ can be derived from the Monte Carlo simulations. The general form of (10) for $N$ countries is:

$\sigma^{2}\left(d_{j k}\right)=\sum_{i=1}^{N} S_{i}^{2} \sigma^{2}\left(\alpha_{i j k}\right)+2 \sum_{\substack{m, n=1 \\ m \neq n}}^{N} S_{m} S_{n} \operatorname{cov}\left(\alpha_{m j k}, \alpha_{n j k}\right)$.

To determine the interval in Equation (2), we proceed as follows:

(1) From the Monte Carlo simulation experiments we compute the error of computed deposition due to a single country $c v\left(d_{i j k}\right)$. This is also the error of the transfer coefficients $c v\left(\alpha_{i j k}\right)$ because $d_{i j k}=S_{i} \alpha_{i j k}$. Results from many different source-receptor combinations should be combined to determine a single 'characteristic' error (e.g. an average or upper limit value) that can be applied to every transfer coefficient. For consistency with the rest of this paper, we express this characteristic error as a coefficient of variation, $c \hat{v}(\alpha)$.

(2) We compute the variance of each transfer coefficient from $\sigma^{2}\left(\alpha_{i j k}\right)=\left[\alpha_{i j k} \cdot c \hat{v}(\alpha)\right]^{2}$. We then substitute $\sigma^{2}\left(\alpha_{i j k}\right)$, together with covariance estimates in Equation (10) to compute the variance of deposition in each grid element, $\sigma^{2}\left(d_{j k}\right)$.

The $\delta_{j k}$ in Equation (2) can be taken as a confidence interval:

$$
\delta_{j k}=\gamma \cdot \sigma\left(d_{j k}\right)
$$

where $\gamma=1.64$ for a symmetric $90 \%$ confidence interval, 1.96 for a symmetric $95 \%$ confidence interval, and so on.

For illustration we assign $c \hat{v}(\alpha)$ a value in the upper range of the error due to parameter uncertainty of the two source-receptor combinations in this paper $(20 \%)$. We also neglect covariance in Equation (10) and take $\delta_{j k}$ as the bounds of a symmetric $90 \%$ confidence interval $(\gamma=1.64)$. In Fig. 6 we show a map of Europe with computed isolines of 2 and $5 \mathrm{~g} \mathrm{~m}^{-2} \mathrm{a}^{-1}$ total sulfur deposition together with their error bounds for a scenario of $30 \%$ reduction of $1980 \mathrm{SO}_{2}-\mathrm{S}$ emissions throughout Europe. These bounds range from a few tens to a few hundreds of $\mathrm{km}$ around the computed isolines. Figure 6 illustrates that a constant error (i.e. a constant coefficient of variation) applied to transfer coefficients can produce very irregular spatial patterns of computed deposition error.

\section{CONCLUSIONS}

1. The framework presented herein, including the uncertainty taxonomy, was helpful to organize the error analysis of a LRT model.

2. Covariance between parameter distribution can have an important effect on computed model error, and can either exaggerate or reduce model error compared to the uncorrelated case.

3. For the specific cases studied, it is more important to know the dispersion of input frequency distributions than the shapes of these distributions.

4. For the source-receptor combinations examined, a $20 \%$ parameter uncertainty (expressed as coefficient of variation of a triangular distribution) yields a $15-22 \%$ total sulfur deposition error.

5. Model experiments presented in this paper indicate that parameter uncertainties tend to compensate for one another in computing total sulfur deposition error.

6. The relationship between input parameter uncertainty and output deposition error is approximately proportional.

7. The state variables with the largest errors were $\mathrm{SO}_{2}$ air concentration and wet deposition; the smallest was total sulfur deposition. 
Total sulfur deposition $\left(\mathrm{g} / \mathrm{m}^{2} \mathrm{yr}^{-1}\right)$

Scenario: $\quad 30 \%$ reduction all Europe

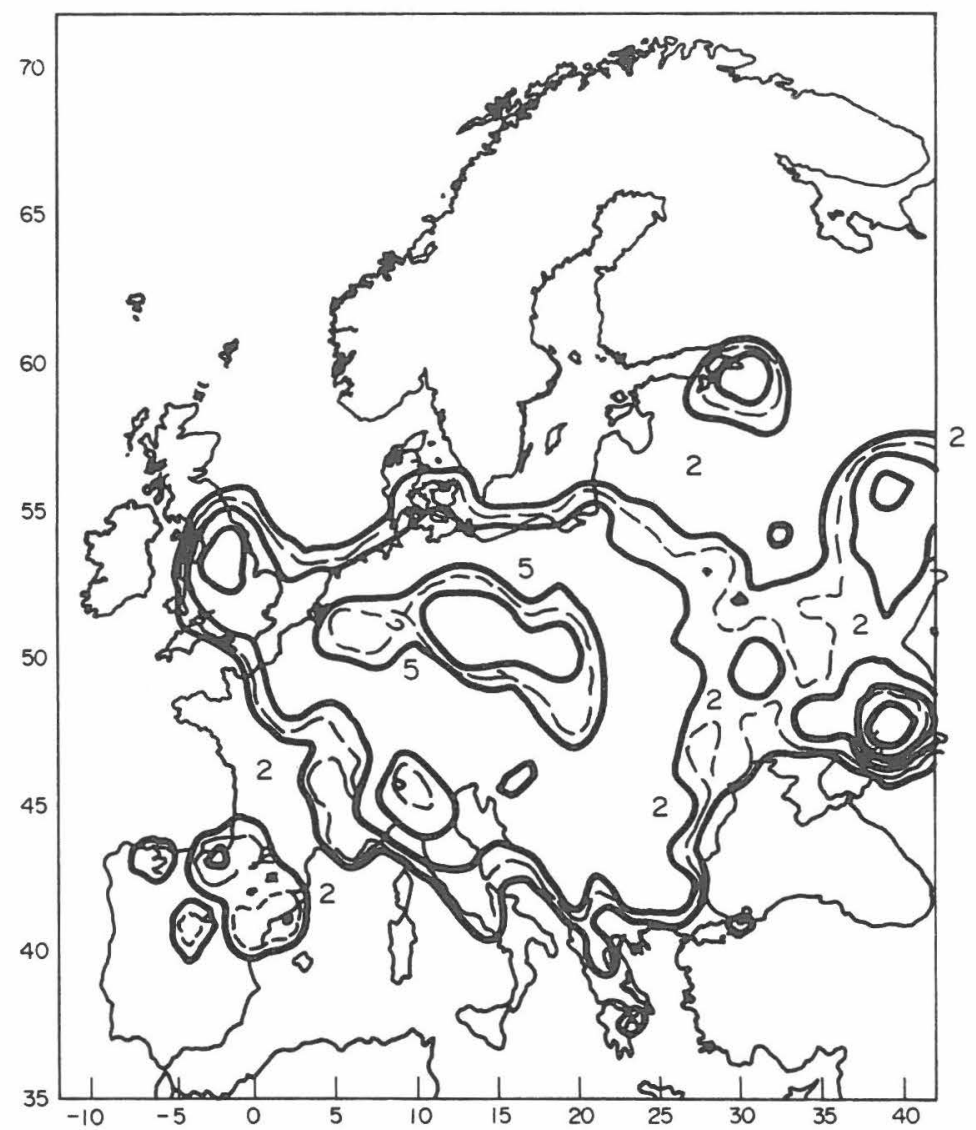

Emissions from Europe

(C) IIASA

Fig. 6. Computed deposition of 2 and $5 \mathrm{~g} \mathrm{~m}^{-2} \mathrm{a}^{-1}$ (dashed lines) with error bounds interval (solid lines) due to $20 \%$ coefficient of variation of all transfer coefficients. Calculations based on EMEP annual average transfer matrix with October 1978-September 1982 meteorology, and assumption of $30 \%$ reduction of sulfur emissions in each country relative to their 1980 levels.

Our general conclusion from this analysis and from our study of the literature is that it now seems feasible to not only model the long-range transport of air pollutants, but also to quantify model error. Yet this paper is only a very modest step in this direction. For example, in our parameter uncertainty analysis we have examined only two source-receptor combinations, whereas in order to generalize results for all Europe, several more should be studied. The issue of combining uncertainties has not been treated in this paper; nor has the problem of covariance between transfer coefficient errors which could either increase or decrease the error bounds depicted in Fig. 6. These and many other unanswered questions suggest that error analysis of long-range transport models (and other types of air pollution models as well) is an open and important area of research.

Acknowledgements-The authors wish to acknowledge W. Schöpp who wrote most of the software used for the calculations presented herein, and A. Eliassen and J. Saltbones and the EMEP Meteorological Synthesizing Center-West for providing needed data together with helpful comments on the analysis. The authors are also grateful to $\mathrm{R}$. van Aalst, R. Berkowicz, A. Cocks, G. Gravenhorst, A. Holtslag, S. Joffre, W. Klug, G. Nordlund, S. Pitovranov, J. Saltbones and J. den Tonkelaar, for participating in discussions at IIASA regarding atmospheric uncertainty analysis. In addition L. Hordijk and M. Posch kindly reviewed the entire manuscript of this paper.

This work was supported in part by an agreement between IIASA and the Institute for Meteorology and Water Management in Warsaw, J. Pruchnicki coordinator. 


\section{REFERENCES}

Alcamo J. (1987) Uncertainty of forecasted sulfur deposition due to uncertain geographic distribution of emissions. Paper presented to 16th International Technical Meeting on Air Pollution Modeling and Its Applications, Lindau, F.R.G., 6-10 April 1987.

Alcamo J. and Bartnicki J. (1985) An approach to uncertainty of a long-range air pollutant transport model. IIASA Working Paper WP-85-88, International Institute for Applied Systems Analysis, A-2361 Laxenburg, Austria.

Alcamo J. and Bartnicki J. (1986) Effect of a non-linear sulfur removal coefficient on computed sulfur source-receptor relationships: some model experiments. Paper presented to EURASAP Symposium on Interregional Air Pollutant Transport, Budapest, 22-24 April 1986. Extended abstracts to be published by International Institute for Applied Systems Analysis, A-2361 Laxenburg, Austria.

Alcamo J., Hordijk L., Kämäri J., Kauppi P., Posch M. and Runca E. (1985) Integrated analysis of acidification in Europe. J. envir. Mngmt. 21, 47-61.

Alcamo J. and Posch M. (1986) Effect of interannual meteorological variability on computed sulfur deposition in Europe. In Atmospheric Computations to Assess Acidification in Europe: Work in Progress (edited by Alcamo J. and Bartnicki J.), IIASA Research Report 86-5. International Institute for Applied Systems Analysis, A2361, Laxenburg, Austria.

Beck B. and van Straten G. (1983) Uncertainty and Forecasting of Water Quality. Springer, Berlin.

Burges S. S. and Littenmaier D. P. (1975) Probabilistic methods in stream quality management. Water Resour. Bull. 11, 115-130.

Carson D. L. (1986) A report on the symposium on uncertainty in modelling atmospheric dispersion. Atmospheric Environment 20, 1047-1049.

Clifford A. A. (1973) Multivariate Error Analysis. Applied Science, Essex, England.

Demerjian K. L. (1984) Quantifying uncertainty in longrange transport models: a summary of the AMS workshop on source and evaluation of uncertainty in long-range transport models, Woods Hole, MA, September 1984. Bull. Am. Met. Soc. 66, 1533-1540.

Eliassen A. (1978) The OECD study of long-range transport of air pollutants: long range transport modelling. Atmospheric Environment 12, 479-487.

Eliassen A. and Saltbones J. (1975) Decay and transformation rates of $\mathrm{SO}_{2}$ as estimated from emission data trajectories and measured air concentrations. Atmospheric Environment 9, 425-429.

Eliassen A. and Saltbones J. (1983) Modeling of long-range transport of sulfur over Europe: a two-year model run and some model experiments. Atmospheric Environment 17, 1457-1473.

Fedra K., van Straten G. and Beck B. (1981) Uncertainty and arbitrariness in ecosystems modelling: a lake modelling example. Ecol. Modeling 13, 87-110.

Fox D. (1984) Uncertainty in air quality modeling, a summary of the AMS workshop on quantifying and communicating model uncertainty, Woods Hole, MA, September 1982. Bull. Am. Met. Soc. 65, 27-36.

Freeman D. L., Egami R. T., Robinson N. F. and Watson J. G. (1986) A method for propagating measurement uncertainties through dispersion models. J. Air Pollut. Control Ass. 36, 246-253.

Gardner R. H., Huff D. D., O'Neill R. V. Mankin J. B., Carney J. and Jones J. (1980) Application of error analysis to a marsh hydrology model. Water Resour. Res. 16, 659-664.

Högstrom U. (1979) Unpublished work presented in Anon, The OECD Programme on Long-Range Transport of Air Pollutants, Second Edn. OECD, Paris.

Hordijk L. (1985) A model for evaluation of acid deposition in Europe. In Systems Analysis and Simulation 1985 (edited by
Sydow A., Thoma M. and Vichnevetsky R.), pp. 30-39. Akademie, Berlin.

Lehmhaus J., Saltbones J. and Eliassen A. (1986) A modified sulfur budget for Europe for 1980. Unpublished report of the EMEP Meteorological Synthesizing Center, West, Norwegian Meteorological Institute, Oslo, EMEP/MSCW Report 1/86.

McMahon T. A. and Denison P. J. (1979) Empirical atmospheric deposition parameters-a survey. Atmospheric Environment 13, 571-585.

Morgan M. G., Morris S. C., Henrion D., Amaral A. L. and Rish W. R. (1984) Technical uncertainty in quantitative policy analysis - a sulfur pollution example. Risk Anal. 4, 201-216.

Nordlund G. (1986) Local deposition of sulfur: a comparison of Finnish estimates and EMEP model values. In Atmospheric Computations to Assess Acidification in Europe: Work in Progress (edited by Alcamo J. and Bartnicki J.), IIASA Research Report 86-5.

OECD (Organization for Economic Cooperation and Development) (1979) The OECD Programme on Longrange Transport of Air Pollutants, Second Edn. OECD, Paris.

O'Neill R. V., Gardner R. H. and Carney J. H. (1982) Parameter constraints in a stream ecosystem model: incorporation of a priori information in Monte Carlo error analysis. Ecol. Modeling 16, 51-65.

Petterssen S. (1956) Weather Analysis and Forecasting. McGraw-Hill, New York.

Tilden J. W. and Seinfeld J. H. (1982) Sensitivity analysis of a mathematical model for photochemical air pollution. Atmospheric Environment 16, 1357-1364.

Tiwari J. L. and Hobbie J. E. (1976) Random differential equations as models of ecosystems-II. Initial conditions and parameter specifications in terms of maximum entropy distributions. Math. Biosci. 31, 37-53.

U.S. National Research Council (1983) Acid Deposition. National Academy Press, Washington, D.C.

\section{APPENDIX A: EMEP MODEL EQUATIONS}

The theoretical formulation of the EMEP model is described in Eliassen and Saltbones (1975) and Eliassen (1978). The latest published version can be found in Eliassen and Saltbones (1983). The EMEP model consists of two differential and five algebraic equations. Denoting $\mathrm{SO}_{2}$ air concentration by $c_{1}$ and $\mathrm{SO}_{4}^{2-}$ air concentration by $c_{2}$ (both expressed in sulfur units), the basic model equations can be written in the following form:

$$
\begin{aligned}
& \frac{D c_{1}}{\mathrm{~d} t}=\left(\frac{v_{\mathrm{d}}}{h}+k_{\mathrm{t}}+k_{\mathrm{w}}\right) c_{1}+(1-\alpha-\beta) \frac{Q}{h} \\
& \frac{\mathrm{D} c_{2}}{\mathrm{~d} t}=-\kappa c_{2}+k_{\mathrm{t}} c_{1}+\beta \frac{Q}{h} .
\end{aligned}
$$

The operator $\mathrm{D} / \mathrm{d} t$ is the total time derivative, $Q$ is the sulfur emission per unit area and time. Other symbols are given in Table 2. Equations (A.1) and (A.2) are solved in two steps. Trajectories are first calculated using the method described by Petterssen (1956). Then, the mass-conservation equations (A.1) and (A.2) are solved on these trajectories to compute concentrations at the receptor points. Dry deposition of sulfur at a particular grid location is computed by applying deposition velocities to time-averaged $\mathrm{SO}_{2}$ and $\mathrm{SO}_{4}^{2-}$ concentrations:

$$
d_{\mathrm{d}}=\left(\bar{c}_{1} \cdot v_{\mathrm{d}}+\bar{c}_{2} \cdot v_{d s}\right) T
$$

where:

$\bar{c}_{1}$ is the time-averaged $\mathrm{SO}_{2}$ concentration, $\bar{c}_{2}$, the time-averaged $\mathrm{SO}_{4}^{2-}$ concentration, $d_{\mathrm{d}}$, the dry deposition of sulfur during time $T$, 
and $T$, the period of the transport (usually 1 year in the EMEP model).

Wet deposition is estimated indirectly through the following procedure. First, the mean concentration of sulfur in precipitation, $\hat{c}_{3}$, is estimated from the computed mean concentration of sulfate during the rain $\hat{c}_{2}$ using a linear relationship:

$$
\hat{c}_{3}=a \hat{c}_{2}+b
$$

where $\hat{c}_{2}$ and $\hat{c}_{3}$ are averaged over time $T$. The precipitationweighted mean $\hat{c}_{2}$ is calculated from

$$
\hat{c}_{2}=\frac{1}{P} \sum_{i} p_{i} \cdot c_{2, i}
$$

where $p_{i}$ is the amount of precipitation observed on day $i, c_{2, i}$ is the corresponding calculated mean air concentration of $\mathrm{SO}_{4}^{2-}$ and $P$ is the total amount of precipitation during time $T$ in a specific grid element. Days without precipitation do not contribute to $\hat{c}_{2}$. The value of wet deposition in the model $d_{t \prime}$ is computed as

$$
d_{\mathrm{w}}=\hat{c}_{3} \cdot P
$$

and total deposition of sulfur $d_{\mathrm{t}}$ is:

$$
d_{\mathrm{t}}=d_{\mathrm{d}}+d_{\mathrm{w}} .
$$

The units of $d_{\mathrm{d}}, d_{\mathrm{w}}$ and $d_{\mathrm{t}}$ are $\mathrm{g} \mathrm{m}^{-2} \mathrm{t}^{-1}$.

The numerical grid of the EMEP model covers all of Europe, a large part of the Atlantic Ocean and a small part of $\mathrm{N}$ Africa. It consists of 39 points in the $x$-direction and 37 in the $y$-direction. The grid size is $150 \mathrm{~km} \times 150 \mathrm{~km}$. 
